\title{
VARIA SUERTE DE LA RECEPCIÓN DE LA LITERATURA CLÁSICA: LOS CASOS DE RAMÓN GÓMEZ DE LA SERNA Y FRANCISCO AYALA
}

\author{
Jordi Redondo \\ Universitat de València \\ Lordi.Redondo@valencia.edu
}

\section{RESUMEN}

Se recogen en este trabajo referencias a la literatura clásica, explícitas o implícitas, en dos autores españoles cuyas respectivas obras resultan en muchos aspectos antagónicas: a sus diferentes trayectorias vitales, ya que pertenecen a generaciones distintas, además de que el más joven (Ayala 1906-2009) sobrevivió al otro (Gómez de la Serna, 1888-1963) en más de cuarenta años, se une una muy opuesta práctica de la creación literaria. No ha de sorprender, por tanto, que ambos muestren diferentes acercamientos a la literatura clásica.

PALABRAS CLAVE: recepción, literatura clásica, prosa, novela, cuento, siglo XX.

\section{VARIOUS LUCK OF THE RECEPTION OF THE CLASSIC LITERATURE: \\ THE CASES OF RAMÓN GÓMEZ DE LA SERNA \\ AND FRANCISCO AYALA}

\section{ABSTRACT}

This paper presents the reception of the Classical literature, in a more or less explicit way, in two Spanish prose-writers that created quite opposite literary productions: not only because they belong to two different generations, since the younger (Ayala 1906-2009) lived more than forty years than the older (Gómez de la Serna, 1888-1963), but also because of their contrasting conception of the literary creation. It is therefore not at all surprising that they attest different approaches to the Classical literature.

KeYwords: Reception, Classical literature, prose genres, novel, short story, $20^{\text {th }}$ century.

Los dos autores de que vamos a tratar, y a los que con matices cabe calificar de contemporáneos, comparten escasos rasgos de sus respectivas creaciones literarias. El primero, Ramón Gómez de la Serna, frecuentó los espacios donde pudiera ganar notoriedad, alimentó recursos encaminados a enlazar con la estética de la vanguardia contemporánea y legó una obra literaria de difícil encasillamiento en el sistema de los géneros. El segundo, Francisco Ayala, siguió una trayectoria más discreta, lo que no le impidió componer una obra narrativa de gran solidez. Sí compartieron 
ambos la experiencia del exilio, como tantos otros autores de sus respectivas generaciones. Las páginas que siguen ofrecerán una aproximación a la diferente recepción de la literatura clásica en ambos. Las profundas diferencias de las respectivas obras, como producto de sendas elaboraciones literarias que seguían principios teóricos, técnicas artísticas y recursos estilísticos de distinto cuño, permitirá apreciar la diversidad en que se da la recepción de las literaturas clásicas.

\section{LA LITERATURA CLÁSICA EN LA OBRA DE RAMÓN GÓMEZ DE LA SERNA}

Ramón Gómez de la Serna, o simplemente Ramón, nació en Madrid en 1888 y pronto pudo consagrarse por entero a la creación literaria; ya en 1904 publica su primer libro, Entrando en fuego, y en 1908 se hace cargo de la revista Prometeo, fundada por su padre para favorecer su vocación; en 1915 funda la tertulia del Café Pombo, que pronto se convertiría en referencia obligada para conocer la actualidad de la literatura escrita en Madrid; tras una actividad constante en términos a medio camino entre las tendencias del «agit-prop» y una provocación más tradicional, en la línea más de Larra que de Valle Inclán, el estallido de la guerra en 1936 hizo que Gómez de la Serna abandonara España para exiliarse en Argentina junto a su prometida. Atrás quedaba todo un horizonte vital que no se reanudaría nunca, a pesar de un único viaje en 1949, y que no volvió a hacer. Desencantado de la realidad española, Ramón siguió en Buenos Aires hasta su fallecimiento en 1963. La obra de Ramón es abundante y de difícil clasificación, porque el señuelo del vanguardismo incitó a su autor a difuminar los límites entre los géneros literarios. Cultivó la novela corta, la biografía, el ensayo, el cuento y el teatro. A pesar de no haber publicado poesía como tal, el lirismo de muchas de sus páginas sólo puede ser entendido en clave de composición poética. En el otro polo de su obra, Ramón enlaza con el costumbrismo del ya aludido Larra, del que lo separa su escasa voluntad de denuncia social, y de Mesonero Romanos.

La extensión de la producción ramoniana impide hacer en unas breves páginas un estudio completo de la presencia en ella de la tradición clásica ${ }^{1}$. No obstante, la lectura de una selección de sus greguerías, de las que publicó hasta ocho colecciones -sin contar las antologías- entre 1912 y $1940^{2}$, permite apreciar el conocimiento de las letras grecolatinas por parte de Ramón ${ }^{3}$. Creemos que los fragmentos de Heráclito suministraron al autor el modelo formal e ideológico para sus "Greguerías», Vidal (1988).

${ }^{1}$ La única aportación conocida a esta faceta del arte de Ramón es la breve nota de Ferrer-

${ }^{2}$ Gómez de la Serna (1912, 1914, 1917, 1919, 1935, 1936, 1940).

${ }^{3}$ Nos hemos basado en la edición de Cardona $\left(2002^{11}\right)$. 
y que el nombre mismo de la obra ramoniana reconoce esta deuda. La mayor y más influyente aportación de Gómez de la Serna al horizonte literario hispánico, la greguería, se apoya a nuestro entender en una doble corriente: por una parte, la tradición gnómica tanto filosófica y literaria como popular, con un decisivo entronque ideológico, formal y textual en el pensamiento y los fragmentos de Heráclito, como esperamos mostrar seguidamente; por otra, el gusto de las vanguardias literarias del primer cuarto de siglo por el aforismo, a menudo en corresponsión con imágenes -cuadros, dibujos y grabados, fotografías- y caracterizado por un discurso provocador, basado en los juegos antitéticos, las sinestesias, los retruécanos, los guiños a un lenguaje infantil o aparentemente propio de un orate, y los neologismos ${ }^{4}$.

El propio Gómez de la Serna reconoció haberse inspirado para la creación de sus greguerías en una pléyade de autores, entre los cuales cita a tres de la Antigüedad grecolatina, a Luciano de Samosata, a Eurípides y a Horacio 5 . Del primero cita la frase "cuando graniza en la Tierra, es que tiemblan las vides en la Luna», que no

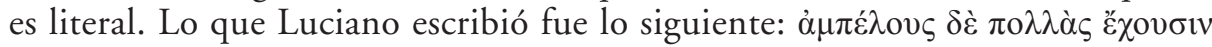

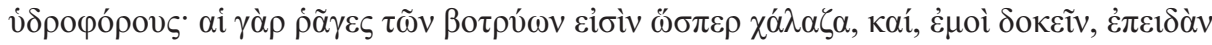

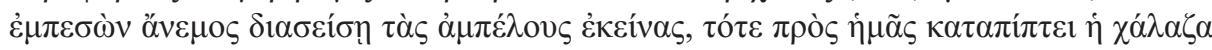

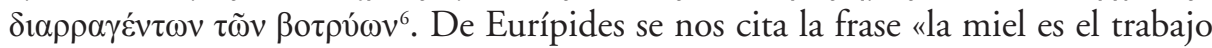
público de las abejas», que no parece hallarse en dicho tragediógrafo. $Y$ de igual modo de Horacio nos dice Ramón que llamaba «saleros» a los ojos, cita que tampoco hemos sido capaces de localizar. Tenemos la impresión de que nuestro autor se inventó ambas citas, a menos que procedan de citas erróneas o de traducciones inexactas.

Algunas de las greguerías ofrecen meras imágenes o símbolos, válidas por el contraste entre los horizontes estéticos de ambos mundos, el antiguo y el moderno. No falta en ellas el doble impulso de mitificación y desmitificación, volcado, respectivamente, hacia aquellos aspectos menos y más alejados del poder político e ideológico de la tradición antigua. Así, «el que toma el refresco con dos pajas parece que toca la doble flauta de Pan» (p. 92), «hay nubes que llevan una carta urgente y otras que van a la batalla de las Termópilas sin saber que llegan tarde» (p. 134), «las conchas de las playas son los restos de los arroces que se come Neptuno» (p. 136),

${ }^{4}$ En general, para la definición de la greguería, véanse Nicolás (1988) y Bonilla Gago (1988). También ha de verse Cardona (1957), sobre el carácter panteísta del pensamiento de Ramón, que consideraba todos los entes formados por átomos, lo que abre la puerta a una comprensión homológica del mundo. Hasta qué punto el interés de Ramón por la física atómica se debía tan sólo a las lecturas de los modernos, o habría tenido también una apoyatura en la lectura de los filósofos presocráticos, es cuestión sobre la que no disponemos de espacio sino para apuntarla.

${ }^{5}$ Ramón Gómez de la Serna, prólogo a Total de Greguerías, Madrid 1962², pp. 38-39.

${ }^{6}$ Luciano, Historia verdadera 24: «Poseen muchas viñas que suministran agua, ya que sus granos son como granizo, hasta el punto de que soy de la opinión de que cuando un viento sacude con fuerza esas viñas al abatirse sobre ellas, cae entonces sobre nosotros el granizo al deshacerse los racimos» (trad. J. Redondo). 
«las Parcas no cortan ya con la tijera el hilo de las existencias, sino con ese aparato con que el chico de la tienda corta el bramante» (p. 171), «el zodíaco es algo así como la lista o menú del restaurante de los dioses» (p. 176), «el camarero que se olvida de abrir la botella, es un hijo de Tántalo» (p. 205), «el griego tiene la doble categoría de ser él y un antepasado» (p. 222), «las Venus antiguas nos sonríen desde el cuarto de baño de la inmortalidad» (p. 253) y «los griegos se morían soltando palabras griegas por la boca» (p. 274). Hay incluso greguerías de neto fuste anticlásico, o que al menos reivindican un clasicismo más contenido y auténtico: «los que fechan cualquier cosa con números romanos -MCMXXXV- son unos MMMEMOS» (p. 172).

En otras greguerías hallamos, en cambio, el reflejo de una idea antigua: en «el tiempo no corre más gracias a las tortugas» (p. 105) hay un guiño a la alegoría de Zenón de Elea7. En «¿en la muerte se sueña?: he aquí el terrible problema» (p. 128) aparece el por doquier presente Heráclito, lo mismo que en «sólo al morir nos acordamos de que ya morimos al nacer» (p. 155), en «si la muerte no se pareciese al sueño, la [sic] sería mucho más difícil el sorprendernos (p. 224), en «-¿Vives? -Sí. -¿Mueres? -Sí. - ¿Entonces? -Vivo y muero al mismo tiempo, que eso es el vivir» (p. 228), en «nunca es mañana; siempre es hoy» (p. 228), en "ies que saben los que duermen quiénes son?» (p. 229), y en «el no haber muerto nunca es lo único que distingue a los vivos de los muertos» (p. 230).

Veamos acto seguido algunos de los aforismos de Héraclito, cuya mera lectura clarificará nuestra opinión: «Muerte es cuantas cosas vemos al despertar, sueño cuantas vemos al dormir»"; «el hombre en la noche enciende para sí una luz, cuando, al morir, se han apagado sus ojos; viviendo toca al muerto, al dormir, cuando se han apagado sus ojos; despierto toca al que duerme»"; "no se debe hacer ni decir como los que duermen ${ }^{10}$; «los que duermen son hacedores y colaboradores de lo que sucede en el mundo" ${ }^{11}$; "como una misma cosa está en nosotros lo viviente y lo muerto, así como lo despierto y lo dormido, lo joven y lo viejo; pues éstos, al cambiar, son

${ }^{7}$ Zenón de Elea frg. 80 (= Simplicio, Física 1014,9-1015,2): «El argumento es llamado 'Aquiles’ porque en él se ocupa de Aquiles, quien, según dice el argumento, no puede dar alcance a la tortuga que persigue. [...] Supóngase que se trata de un estadio. Una tortuga avanza a partir de la mitad del estadio, y Aquiles avanza diez veces más en el mismo tiempo, Aquiles, desde el comienzo del estadio, inicia la persecución de la tortuga, y avanza medio estadio, de modo que llega a la mitad del mismo, de donde partió la tortuga. Pero ésta avanzó ya la décima parte de la mitad restante del estadio. Aquiles recorre entonces la décima parte de esta mitad del estadio; pero la tortuga avanzó la décima parte de la décima parte de la mitad restante. Y mientras quede una décima parte de cualquier distancia, y ella tenga a su vez una décima parte, la tortuga estará siempre delante de Aquiles, y jamás ninguno de los dos podrá recorrer la totalidad del estadio» (trad. N. L. Cordero).

${ }^{8}$ Heracl. 22 B 21 (= Clem. Strom. III 21). Todas las traducciones de Heráclito se han tomado de Eggers Lan \& Juliá (1978).

${ }^{9}$ Heracl. 22 B 26 (= Clem. Strom. IV 141).

${ }^{10}$ Heracl. 22 B 73 (= Marco Ant. IV 46).

${ }^{11}$ Heracl. 22 B 75 (= Marco Ant. IV 46). 
aquellos, y aquellos, al cambiar, son éstos; para las almas es placer o muerte volverse humedad [...]. Nosotros vivimos la muerte de aquellas y aquellas viven nuestra muerte» ${ }^{12}$. ¿Pudo Ramón conocer por medio de traducciones la obra de Heráclito? Creemos que sí, ya que en la cultura francesa, que Ramón frecuentó siempre, había aparecido en 1887 la traducción de Tannery ${ }^{13}$.

Hay además otro autor que puede hallarse tras algunas de estas greguerías. Nos referimos al poeta Calímaco, algunos de cuyos epigramas podrían haber inspirado a Ramón ${ }^{14}$. Véase si no los epigramas IX, XIII y XIV:

IX «Sagrado sueño duerme aquí Saón, el hijo de Dicón, ciudadano de Acanto: no digas que los hombres de bien mueren ${ }^{15}$. «¿Acaso aquí a tus pies descansa Caridas? -Si hablas del hijo de Arimas de Cirene, aquí es. -¿Qué hay de ese abismo? -Mucha oscuridad. $-\mathrm{Y}$ de salidas, ¿qué? -Mentira. -¿YY de Plutón? -Cuentos. - ¡Por perdido me doy! -Esta noticia mía, tenedla por veraz; pero si quieres una agradable, vale un buey grande en el Hades uno de Pela ${ }^{16}$. «-¿Quién a ese dios conoce de verdad, al Mañana? Pues a ti, Carmis, que ayer estabas ante nuestros ojos, llorando te enterrábamos de un día a otro; nada más cruel vió su padre Diofonte» ${ }^{17}$.

Por otra parte la ironía, tan presente de nuevo en Heráclito, se echa de ver en greguerías como las siguientes: «no gozamos bien el canto del ruiseñor, porque siempre dudamos de que sea el ruiseñor» (p. 71) ${ }^{18}$. En «me inquietan las escaleras mecanizadas, porque revelan cómo nos conduce siempre la fatalidad, aunque creamos estar inmóviles» (p. 187), hallamos la idea del hombre como juguete del destino, $\tan$ frecuente en la tragedia y la historiografía antiguas.

En ocasiones resulta en extremo comprometido pensar que Ramón alude a un texto clásico. Así, cuando dice «el arco del violín cose, como aguja con hilo, notas y almas, almas y notas» (p. 63), el recuerdo de Heráclito se nos hace del todo evidente, pero falta un apoyo textual más preciso ${ }^{19}$. Este motivo, sin embargo, es

${ }^{12}$ Heracl. 22 B 77 (= Numenio frg. 35 T).

${ }^{13}$ Tannery $(1887,110-128)$.

${ }^{14}$ Ortega Garrido $(2012,304)$ señala la influencia del epigrama, pero lo atribuye a la literatura romana: «El epigrama revive tal vez en la greguería de Gómez de la Serna, donde el humorismo y la pequeña sátira, ingredientes de las breves composiciones en prosa de Ramón, se acercan al género de Roma en intención y, especialmente, en concepción».

${ }^{15}$ Call. ep. IX.

${ }^{16}$ Call. ep. XIII.

${ }^{17}$ Call. ep. XIV.

${ }^{18}$ Heracl. 22 B 126 (= Tzetzes, escolio a Exeg. Il.): «El antiguo Heráclito de Éfeso era llamado asombroso a causa de lo oscuro de sus palabras: las cosas frías se calientan, lo caliente se enfría, lo húmedo se seca, lo reseco se humedece»; 22 B 111 (= Estobeo, Flor. I 177): «La enfermedad hace a la salud agradable y buena; el hambre, a la saciedad; la fatiga, al reposo» (trad. C. Eggers Lan \& V. Juliá).

${ }_{19}$ Cf. Heracl. 22 B 51 (Hipol. Ix 9, 2) «No entienden cómo, al diverger, se converge consigo mismo; armonía propia del tender en direcciones opuestas, como la del arco y la lira»; apócrifo, citado por Aristóteles, Etica Nicomaquea VIII 2, 1155 b: «Lo opuesto concuerda y de las cosas discordantes surge la más bella armonía» (trad. C. Eggers Lan \& V. Juliá). 
tan constante en Ramón que su frecuencia obliga a considerar la alta plausibilidad de una inspiración en Heráclito: «la golondrina llega de tan lejos porque es flecha y arco al mismo tiempo» (p. 85). Por otra parte, en la greguería «la luna y el sol no tienen más que una sola cama para descansar y por eso la una trabaja cuando el otro duerme» (p. 181) hay razones para pensar en un eco hesiódico ${ }^{20}$.

En su extensa obra narrativa, Ramón halla más abundante ocasión para sus ejercicios de evocación en las paradojas del mundo moderno que en las páginas de los autores clásicos. Cuando la tradición grecolatina se asoma a su obra, lo hace con idéntica función desmitificadora ${ }^{21}$ : «El equilibrio de la vida se sostiene si la peluquería primera sigue funcionando. El aire de la Grecia magna en que todos aclaraban sus mentes debía ser un aire de peluquería ${ }^{22}$. Nuevamente creemos advertir algún eco hesiódico, como cuando se sitúa en el ardor del estío la eclosión de la belleza de una muchacha, y justo a renglón seguido Ramón apunta: «se podría decir observando ese fenómeno que si no hubiese mujeres tan guapas como Adelaida, la gente no llegaría nunca a su casa, pues perdida la ilusión de la mujer que va delante los hombres serían bueyes cansinos que tardan mucho en avanzar con los cuernos caídos y la baba densa ${ }^{23}$.

A manera de conclusión, y en relación con la influencia ejercida por Ramón en las generaciones literarias posteriores, nos parece aceptable la observación de su papel como precursor de la poesía de los llamados «novísimos». El lirismo de las greguerías coincide con un aparente homenaje al pasado remoto, pero que en realidad esconde un juego de espejos en el que todo original resulta deformado.

\section{LA TRADICIÓN CLÁSICA EN LA OBRA DE FRANCISCO AYALA}

Francisco Ayala (Granada, 1906) sigue una trayectoria muy similar a la de Sender. Como el aragonés, Ayala comparte la causa republicana, sufre a partir de 1939 un largo exilio y desarrolla una fecunda actividad intelectual y docente en América,

${ }^{20}$ Cf. Hesíodo, Teogonía, 745-755: «También se encuentran allí las terribles mansiones de la oscura Noche cubiertas por negruzcos nubarrones. Delante de ellas, el hijo de Jápeto sostiene el ancho cielo, apoyándolo en su cabeza e infatigables brazos, sólidamente, allí donde la Noche y la Luz del día se acercan más y se saludan entre ellas pasando alternativamente el gran vestíbulo de bronce. Cuando una va a entrar, ya la otra está yendo hacia la puerta, y nunca el palacio acoge entre sus muros a ambas, sino que siempre una de ellas fuera del palacio da vueltas por la tierra y la otra espera en la morada hasta que llegue el momento de su viaje» (trad. A. Pérez Jiménez).

${ }^{21}$ Sobre la reelaboración del material mítico en Gómez de la Serna, véase Elwes Aguilar (2008).

${ }^{22}$ R. Gómez de la Serna, «Peluquería feliz», en Zlotescu et al. (eds.) (2002, 86).

${ }^{23}$ R. Gómez de la Serna, «La hija del verano», en Zlotescu et al. (eds.) $(1999,479)$. Compárese Hesíodo, Trabajos y días, 582-588: "Cuando el cardo florece y la cantora cigarra, posada en el árbol, derrama sin cesar por debajo de las alas su agudo canto, en la estación del agotador verano, entonces son más ricas las cabras y mejor el vino, más sensuales las mujeres y los hombres más débiles, porque Sirio les abrasa la cabeza y las rodillas, y su piel está reseca por la calina» (trad. A. Pérez Jiménez). 
en su caso en Argentina, Puerto Rico y Estados Unidos. Vuelto del exilio en el año 1976, falleció en el 2009. Pero, a diferencia de Sender, de Ayala contamos con una merecida, magnífica y cuidada edición de su prosa completa ${ }^{24}$, además de con una ya notable tradición investigadora ${ }^{25}$. Facilita mucho nuestra labor el hecho de disponer, reunida y en riguroso orden cronológico, de toda la obra de un autor ${ }^{26}$. Otra fundamental diferencia entre Sender y Ayala estriba en que el granadino no sólo muestra una mucho más cabal formación literaria, sino que también ha desarrollado una labor como ensayista de bastante mayor enjundia, más allá incluso de los estrictos límites de la crítica literaria. Por otro lado, ambos autores, Ayala y Sender, se oponen a Ramón no sólo en el plano ideológico -tanto el estrictamente literario como el del compromiso político-, sino también en cuanto que sus respectivas obras ofrecen, y muy en especial la de Ayala, una obra narrativa de mayor calado, menos efectista en apariencia, pero más cuajada desde el punto de vista de la elaboración. Por oposición a Ramón y a Sender, Ayala sí poseía una sólida formación profesional, en su caso como jurista.

De Ayala se ha escrito que su obra se inserta en una veta narrativa caracterizada por la deshumanización y el intelectualismo, cuyo contrapeso son, respectivamente, la ironía y el sentido de la realidad. Ilustres antecedentes de nuestro autor habrían sido Aldous Huxley, Thomas Mann y, en la literatura española, Ramón Pérez de Ayala. Pero hay que tener siempre presente a Cervantes: el primer relato de Ayala, la novela corta Tragicomedia de un hombre sin espiritu, empieza con el hallazgo

${ }^{24}$ Francisco Ayala, Narrativa Completa, Madrid, Alianza Editorial, 1993. Debe apuntarse que la edición fue posible gracias al concurso del Ministerio de Cultura, habida cuenta de que con ella se homenajeaba al ganador del Premio Cervantes en su convocatoria de 1991. Cabe señalar que, con anterioridad a este galardón, Ayala había recibido los premios de la Crítica (1972, por El jardín de las delicias), el Nacional de Narrativa (1982) y el Nacional de las Letras Españolas (1988), y que ha sido luego distinguido con el Premio Príncipe de Asturias de las Artes (1998). Por otra parte, y si más arriba ya destacábamos el lirismo de Ramón y la calidad de la obra poética de Sender, hay que hacer también mención del magnífico lirismo de Ayala, cf. Gil (1992), hasta el punto de que de algunos textos puede hablarse de "poemas en prosa» (Gil 1992, 40).

${ }^{25}$ Amorós (1973), Vázquez Medel (1992), Hernández Guerrero (1992a, 1992b), Matamoro (1992). Cáceres Sánchez (1992); Paredes Núnez (1992); Fortes Fernández, Hernández Guerrero \& Sánchez Garrido (1993); Orozco Vera (1998). Especial mención merece la monografía de López Calahorro (2008), en la que se resalta la importancia de la recepción de Tácito, Lucano y Plinio como autores principales.

${ }^{26}$ Más cuando se trata de una obra de tan dilatada trayectoria, que arranca en 1925 con Tragicomedia de un hombre sin espiritu, y que cuenta con abundantes títulos: Historia de un amanecer (1926), El boxeador y un ángel (1929), Cazador en el alba (1930), El hechizado (1944), La cabeza del cordero (1949), Los usurpadores (1949), Historia de macacos (1955), Muertes de perro (1958), El fondo del vaso (1962), De raptos, violaciones y otras inconveniencias (1966) y El jardín de las delicias (1971). Debe considerarse a parte su obra crítica, que consta de los ensayos titulados La estructura narrativa (1970) y Novela española actual (1977). 
de un manuscrito, el mismo recurso literario empleado por Cervantes al comienzo de la segunda parte del Quijote; y su última obra creativa publicada, El jardin de las delicias, retoma el argumento del capítulo LI del Quijote, de nuevo. Es cierto que parte de las alusiones a la literatura y la cultura clásicas de Ayala no pasan de la condición de tópicas ${ }^{27}$. Él mismo reconoce en una entrevista que su formación clásica arrastra la grave deficiencia del desinterés provocado por un profesor de latín del que no guarda buena memoria ${ }^{28}$.

El primer Ayala es todavía un prosista apegado a un estilo decimonónico, costumbrista en la trama y el escenario, cargado de un escasamente atractivo retoricismo y todavía falto de un estilo característico. Su primera publicación, titulada Tragicomedia de un hombre sin espiritu, tiene como punto de inflexión de su argumento la lectura, por parte del protagonista, de una Teoría de la metempsicosis. Sin embargo, más allá de algunas alusiones de escaso interés, la tradición clásica huelga por su ausencia. En Historia de un amanecer, publicada tan sólo un año más tarde, se advierten signos de un giro importante en más de un sentido, en lo que se ha llamado la «época vanguardista» de Ayala. La frase se hace más dúctil, aunque aún no lo bastante ágil; comienzan a aparecer ecos de la literatura y el mundo antiguos ${ }^{29}$; se plantea una renovación del modelo estético, como expresamente se formula en la p. 183: «Manos rudas escribirán con rudos trazos los cantos nuevos. Nacerán los poemas con el ritmo fecundo de las máquinas, en los talleres o en el campo, acompañando al trabajo placentero. Podremos aspirar a un nuevo y más alto clasicismo, bajo una justicia más amplia».

La disquisición dialéctica sobre qué es lo clásico y el clasicismo no agota el caudal de motivos de raigambre grecolatina en Historia de un amanecer. Al final del relato, la muerte del protagonista, Abelardo, pone fin a la Academia revolucionaria como la ejecución de Sócrates significó el fin de su escuela:

-Sí, si... -replicó él, para evitar explicaciones inútiles-. Ya sé de lo que se trata... ¿Y éste es el líquido que destruirá mi persona y descompondrá la máquina infatigable de mi cerebro?... !Oh, qué grande es el poder de Dios!

Tomó la taza en sus manos y apuró lentamente el contenido. $[\ldots]$

${ }^{27}$ Tragicomedia de un hombre sin espiritu, p. 45: «Sus pensamientos eran tristes en extremo, y como es de rigor en tales casos no dejó de acudir a su mente la solución magna de cortar el nudo gordiano; quiero decir que pensó en quitarse la vida» etc. P. 133: «El triunfo es de los audaces», etc.

${ }^{28}$ F. Ayala, entrevista publicada en 'El País', 20/01/2005, en un ciclo organizado por la Biblioteca Nacional a propósito de las bibliotecas personales de los grandes creadores.

${ }^{29}$ La organización secreta, entre política y filosófica, como a medio camino entre los carbonarios y los pitagóricos, recibe el inequívoco nombre de «Academia», lo que queda confirmado en la p. 182, donde se lee: «Pero, ¿̇no has oído, Federico? [...] ¡Que nuestros versos no valen para nada! ¡Que habremos de trabajar!... ¡Y todo porque Platón arrojó de su República a los poetas! » En la p. 209 se lee que una mano es "fuerte y broncínea como la del auriga de Delfos». 
Abelardo, un poco más pálido que de costumbre, pero con ademán seguro, se paseaba lenta, serenamente, entre las caras atónitas de sus compañeros que cruzaban entre sí miradas llenas de consternación. Demetrio golpeaba el suelo con su bastón, muy atento -al parecer-a lo que hacía; don Nazario se enjugaba una lágrima con el dorso de la mano; y aquel hombre indeciso se cubría el rostro... Los demás, como gente secundaria, cuidaban menos de su actitud. Pero todos guardaban silencio.

Solamente Abelardo parecía tranquilo. Su capa gris caía en rectos y severos pliegues a lo largo del cuerpo; su frente lucía, levantada; el pelo le caía desordenado, en mechones; los ojos le brillaban con un brillo seco, y la mano apuntaba al cielo con dulzura. También era dulce su acento.

[...]

Abelardo se desprendió de la ventana y dio algunos pasos vacilantes hasta quedar en el centro de la habitación. Hacia él se tendieron algunos brazos; en algunos labios tembló una pregunta que no fue posible sofocar:

$-\dot{\text { Ya? }}$

-No; todavía no -respondió Abelardo, dejándose caer en una butaca, porque le flaqueaban las piernas.

La comparación con el final del Critón platónico es evidente: también Sócrates decide someterse al sacrificio supremo de la vida, se encuentra reunido con sus discípulos y seres más allegados, toma por propia mano el veneno que le ofrecen, pasea hasta que siente progresar la pócima en su cuerpo, ha de reposar, en fin, cuando el efecto de esta se hace notar.

El cuento «Medusa artificial», escrito en 1928 e incluido en el siguiente libro, El boxeador y el ángel, publicado en 1929, avanza aún más en la incorporación de la tradición clásica. Con ser muy breve, está centrado en la actualización del mito de la Medusa:

-No exagero; cualquier hombre que la mire se quedará de piedra. Mi ondulación es permanente.

Ella:

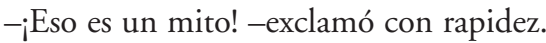

$[\ldots]$

-Un mito, si usted quiere -replicó Gabriel-, pero mi ondulación es garantizada.

Los hombres se quedarán de piedra, y a mí me cumple advertirla del peligro. No sería el primer caso (pp. 299-300).

El cuento de Ayala, que tiene algo de «fabliau» dramatizable, se alimenta también de otros mitemas: el del incesto de padre e hija, y el de la liberación de la doncella; éste último, cuya mejor representación en la mitología griega es el mito de Perseo y Andrómeda, enlaza con el mito de la Gorgona. La recreación de la literatura clásica, más en concreto la griega, se completa con sendas reflexiones adjudicadas a un "coro", que a la vez califica de "héroes» a los protagonistas del relato (pp. 301 y 303). La segunda de las intervenciones del coro es bien explícita, cuando nos dice que «la venganza ejecutada en efigie, semejante al ardid de Perseo, basta para calmar a los benévolos dioses». 
Con el llamado "período vanguardista», iniciado con Cazador en el alba, aparecido en 1930, continúa el tímido empleo de la literatura clásica, al lado de las evocaciones contemporáneas, como fuente de recursos narrativos y estéticos ${ }^{30}$ : así, «las mujeres son tan inaccesibles como las propias deidades del Olimpo»; el alma del protagonista es la propia de un rústico, «de Hércules», y por ello no ha lugar a tildarlo de «nuevo Paris» (p. 313); un rastro de perfume hace las veces de hilo de Ariadna (p. 316); el protagonista «icuántas veces, Hércules sometido, había limpiado aquellas cuadras! »(p. 323).

El Ayala de la postguerra se halla muy lejos de la herencia clásica, lacerado por su condición de exiliado y en deuda con el horizonte ideológico y estético de la America latina. Eso sin menospreciar el largo estadio de postergación de la actividad creadora, y que se había iniciado en 1930, debido a la necesidad de atender las obligaciones académicas del Ayala docente universitario e investigador atento a las parcelas del derecho, la sociología y la crítica literaria, además de las obligaciones impuestas por su cargo de letrado de las Cortes.

La reanudación de las publicaciones literarias no se produce hasta 1949. Escasean las referencias a las culturas antiguas, a las que el autor se había acercado paulatinamente desde sus primeras obras. La tendencia se aprecia ya el mismo 1949 con los dos conjuntos de relatos titulados Los usurpadores y La cabeza del cordero, y en los que desaparece por completo el recurso referencial a la tradición clásica, en beneficio de una prosa en apariencia menos efectista. En el primero, la recreación de episodios históricos de la España medieval y moderna obliga a Ayala a eliminar también de cuajo las alusiones y motivos propios de la literatura, el arte y la sociedad contemporáneas ${ }^{31}$. En el segundo, que debe su título genérico al extenso relato considerado la primera obra de Ayala centrada en el tema del exilio, la variedad de temas no hace que el escritor rompa con la nueva tendencia.

El volumen Historia de macacos, de 1955, retoma en grado levísimo el empleo de la tradición clásica. En «Un cuento de Maupassant» se lee: (...) «el contraste entre el pensamiento de Sócrates y el tono de sus disputas con Xantipa ofrecerá siempre un fácil recurso a la burla aristofánica» (pp. 644-645), una observación impensable en las dos colecciones de relatos de 1949; en el mismo cuento se alude a la cónyuge como "la irritada Juno» (p. 646) o "la Xantipa de turno o su robusta Xantipa» (p. 647) ${ }^{32}$. La siguiente publicación, la novela Muertes de perro, aparecida en 1958,

${ }^{30}$ Sobre la conjunción en Cazador en el alba de horizontes estéticos e ideológicos opuestos, como el urbano y el del campo, véase Bellido Navarro (1998).

${ }^{31}$ Cf. García de Nora $(1979,245)$, que justifica el hondo viraje impreso por el autor a su obra como consecuencia del impacto de la guerra civil, «haciendo pasar al novelista de la posición estética a la ética».

${ }^{32}$ Hiriart (1972b: 61-62) apunta que aquí Ayala funde la Xantipa platónica con el personaje de Xuantipa en R. Pérez de Ayala, Belarmino y Apolonio, Buenos Aires 1956, pp. 37-38. 
sigue en la línea de una muy parca utilización de toda alusión a la cultura antigua: así, por ejemplo, cuando se nos dice que el gobierno de Bocanegra se asemeja, irónicamente, al de Marco Aurelio, el filósofo emperador (p. 746); o cuando se introducen, ya hacia el final de la obra, frases latinas como «tristitia uitae» (p. 802), «consummatum est» (p. 804) y «acqua fontis» (p. 805), o se emplea un helenismo, «coprófaga» (pp. 798-799), para mitigar la obscenidad de la alusión en sus justos términos castellanos $^{33}$. En suma, apenas nada.

En 1962, la publicación de la novela El fondo del vaso modifica levemente esta situación: anotamos expresiones como "prima facie» (pp. 828 y 921), «in articulo mortis y «ecce homo» (p. 834), «in mente» (pp. 842 y 928), «in albis» (p. 875), «lapsus linguae (p. 880), «uox populi» (p. 903), «ad uincula» (p. 926), alusiones al Parnaso (p. 832), a los siete sabios de Grecia (p. 840), al minotauro -«in malam partem», por cierto- (p. 934), a Circe (p. 940). Pero semejante recurso, comparable al empleo de términos ingleses o franceses, parece ralo y pobre. Mayor interés tiene, en primer lugar, un pasaje en el que Ayala se expresa de manera casi programática: «¿Cómo podría yo describir la escena que sorprendí allí? [...] Escena de esas que, en tiempos pretéritos, los escritores solían caracterizar y, a la vez, encubrir pudorosamente, con el velo de frases o vocablos latinos, y que los modernos se complacen, en cambio, describiendo con los más crudos y soeces de su propio idioma; pero que yo, enemigo de tales groserías, quisiera tener habilidad para apuntarla siquiera mediante el olvidado arte del circunloquio. Carente de ella, y puesto que, al igual que la mayoría de mis conciudadanos, ignoro los útiles secretos de la lengua latina, deberé renunciar a todo intento, y dejarle al eventual lector el cuidado de imaginarse lo más infame» (pp. 876-877). Y a renglón seguido, en segundo lugar, Ayala llega incluso a recrearse en el tema de la ignorancia de la cultura clásica: [...] «don Cipriano, como Alonso Quijano, tiene nombre de emperador romano; o griego, que es lo mismo» (p. 879); «[...] confirmaba, de paso, la verdad del apotegma latino que declara: la donna è mobile» (p. 886); «pretendía el gallego, alardeando de su mitológica cultura de Enciclopedia Espasa, que yo había sido un Orfeo al revés, puesto que no había bajado a Ultratumba en busca de mi Eurídice, sino para escapar de ella» (p. 935). Más aún: así como el personaje de José Lino puede analizarse como la inversión del de Orfeo, a lo que también se presta el apellido mismo, el personaje de Corina está modelado como una nueva Penélope $e^{34}$. De ella dice Ayala, en un pasaje de gran carga irónica: «Hay que saber como lo sé yo que esa Corina de tragedia griega no es sino un producto de mi mente acalorada; es menester conocerla como yo la conozco, para advertir la magnitud del disparate» (p. 945).

${ }^{33}$ Cf. Irizarry (1971, 164).

${ }^{34}$ Cf. Hiriart (1972a, 54): «Corina es, ciertamente, en la novela, una reencarnación de Penélope, aunque por supuesto en sentido contrastante, ya que ella a su vez, por oposición al personaje clásico, engaña al marido. La nueva Penélope deshace la labor de su esposo tejiendo una nueva trama» etc. Véase también Hiriart (1972b, 101-102). 
El relato titulado El as de bastos (1963) sigue la pauta menos atractiva de la obra anterior: anotamos las expresiones «in illo tempore» (p. 957), las alusiones a tritones y nereidas y al suplicio de Tántalo (p. 959); Una boda sonada (1962), en cambio, nos presenta a un protagonista de nombre Homero; en Un pez (1963) se alude a "un presente griego" (p. 985) -uso repetido en Magia, II (p. 1154)-; en El rapto (1965) se alude a tirios y troyanos (p. 1021), pero hallamos también un pasaje de resonancias bucólicas ${ }^{35}$.

Con el volumen El jardin de las delicias, aparecido en 1971, vuelven a registrarse tímidas aproximaciones a las literaturas antiguas. El autor titula algunas de las breves piezas Himeneo, Memento mori, Un quid pro quo, o who is who, Gaudeamus o Mímesis, némesis. En el brevísimo relato Por complacer al amante, madre mata a su hijita se revisa el mito de Medea, aunque se le da por completo la vuelta, ya que el infanticidio se produce a instancias del padre; en Actividades culturales se glosa una conferencia cuyo artífice, "con ática galanura", cita el tratado senequiano De senectute (p. 1063); en Diálogo entre el amor y un viejo se retoma el tema del "carpe diem» horaciano y ausoniano (p. 1071); en Magia, II, se alude al Minotauro como «monstruo de tu laberinto» (p. 1155); en Música para bien morir, en fin, se percibe un nítido eco virgiliano: «Las lágrimas de las cosas -me parece que ha dicho esa voz confortadoraocultan apenas una sonrisa de inviolable serenidad» (p. 1191) ${ }^{36}$. Escaso bagaje clásico, lo que tampoco empece la calidad artística y la emoción lírica que destilan muchas de estas páginas, que están entre lo mejor de Ayala.

El relato titulado Glorioso triunfo del príncipe Arjuna, publicado en 1980, merece una especial atención. Se trata del único texto de Ayala en que se percibe una directa inspiración en la literatura clásica grecolatina. Así ocurre, en primer lugar, con frases de hálito inequívocamente épico, al homérico modo: «Fue ésta una visión atroz: hombres de quienes había recibido caricias y halagos siendo niño, otros hombres más jóvenes con quienes había compartido alimentos y juegos y alegrías, sucumbían ahora atravesados por agudas flechas o por la espada. Ya le parecía oír los gritos de dolor y de furia de los combatientes, ya creía ver con sus ojos las heridas abiertas,

${ }^{35}$ «Y así, una mañana de domingo, pocos días después del deplorable episodio, echándose las escopetas al hombro por si algún gazapo se les cruzaba o levantaba el vuelo alguna codorniz, salieron del pueblo para -con pretexto de cacería- tener ocasión holgada de comunicarse sus conturbados pensamientos. Frases embarazadas, vacilantes y alusivas desbrozaron el dificultoso diálogo mientras caminaban campo adentro. Pero cuando ya la fría niebla, a través de la cual debían abordar el tema, se hubo disipado entre ellos, ambos cazadores tomaron asiento en sendos peñascos bajo un árbol y, contemplados por los perros que se habían tendido a sus pies para escucharles, Patricio juntamente y Fructuoso, con tonos dolientes el primero, y despechados e iracundos el otro, lamentaron largamente su desengaño» (p. 1022). Nótese, además del trasfondo escenográfico, la sintaxis y el léxico empleados, e incluso el empleo de un hexámetro, «Patricio juntamente y Fructuoso», que en la tradición castellana remiten a Garcilaso, y en la clásica a Virgilio.

${ }^{36}$ Ayala alude al verso «sunt lacrimae rerum, et mentem mortalia tangunt» (Verg. Aen. I 462), aunque el genitivo «rerum» ha de considerarse objetivo, por lo que la traducción no parece la más correcta. 
los cuerpos ensangrentados, los cadáveres caídos por la tierra» (p. 1202). Pero también advertimos la incorporación de motivos de clara raíz clásica, como cuando se compara la relación entre cuerpo y alma a la de jinete y corcel, expresada por el autor en términos de muy bella factura que evocan la prosa platónica, de la misma manera que el sabio Sendar reencarna la figura del Sócrates de los Diálogos (p. 1198). Veamos como última y patente muestra un uso del todo infrecuente en la prosa de nuestro autor y aun de la narrativa contemporánea, el del símil:

Y ahora la muchachita, fascinada y llena de terror, miraba fija hacia el arma rígida con la que el joven parecía dispuesto a abrir la herida de su tierno vientre. Cual los del sorprendido viajero ante quien de improviso se ha erguido en la selva un reptil amenazante, sus ojos cándidos no lograban desviarse de su amenaza (p. 1200).

RECIBIDO: octubre 2019; ACEPTADO: octubre 2019.

\section{REFERENCIAS BIBLIOGRÁFICAS}

Amorós, A. (1973): Bibliografía de Francisco Ayala, Nueva York.

Bonilla GaGo, J. (1988): «La gran invención de Gómez de la Serna: la greguería», Anthropos 10: 6-14.

CÁCERES SÁNCHEZ, M. (1992): «Francisco Ayala y los estudios sobre el pensamiento estético-literario de José Ortega y Gasset», en A. Sánchez Trigueros \& A. Chicharro Chamorro (eds.), Francisco Ayala, teórico y crítico literario, Diputación Provincial de Granada, Granada, pp. 239-252.

Cardona, R. (1957): «Ramón and the world of things», en R. CARdona, Ramón. A Study of Gómez de la Serna and His Works, Torres, Nueva York, pp. 113-130.

Cardona, R. (2002 $\left.{ }^{11}\right):$ R. Gómez de la Serna. Greguerías, Cátedra, Madrid.

Castro Jiménez, M. D. (2009): “El mito en Ramón J. Sender, Elena Soriano y Francisco Ayala” en J. A. LÓPEZ FÉREZ (ed.), Mitos clásicos en la literatura española e hispanoamericana del siglo XX, vol. I, Madrid, Ediciones Clásicas, pp. 427-439.

EgGers Lan, C. \& Juliá, V. (1978): Los filósofos presocráticos I, Gredos, Madrid.

ElWes Aguilar, O. (2008): "Aspectos míticos del amor en Ramón Gómez de la Serna: entre Don Juan y Pigmalión”, en J. Herrero Cecilia \& M. Montserrat Morales Peco (eds.), Reescrituras de los mitos en la literatura: estudios de mitocritica y de literatura, UCLM, Ciudad Real, pp. 423-433.

Ferrer-Vidal, J. (1988): «Ejemplar visión de Catulo», Cuadernos Hispanoamericanos 461: 124-126.

Fortes Fernández, J. A., Hernández Guerrero, J. A. \& Sánchez Garrido, M. (1993): «Bibliografía de Francisco Ayala» y «Bibliografía sobre Francisco Ayala», Anthropos 140: 70-79 y 79-86.

GarCía de NORA, E. (1979): La novela española contemporánea II, Gredos, Madrid.

GIL, I. M. (1992): «Aspectos líricos en la narrativa de Francisco Ayala», Anthropos 139: 38-41.

Gómez de la Serna, R. (1912): «Greguerías», Prometeo 38.

Gómez de la Serna, R. (1914): Greguerías, Madrid.

Gómez de la Serna, R. (1917): Greguerías, Editorial Prometeo, Valencia. 
Gómez de la Serna, R. (1929): «Novísimas Greguerías», La Gaceta Literaria 3.

Gómez de la Serna, R. (1935): Greguerías 1935, Madrid.

Gómez de la Serna, R. (1936): Greguerías nuevas 1936, Cruz y raya 39.

Gómez de la Serna, R. (1940): Greguerías, Espasa-Calpe, Buenos Aires.

Gómez de la Serna, R. (1962²): "Prólogo", Total de Greguerías, Aguilar, Madrid, pp. 38-39.

Hernández Guerrero, J. A. (1992a): «La teoría literaria de Francisco Ayala», en A. SÁnchez Trigueros \& A. Chicharro Chamorro (eds.), Francisco Ayala, teórico y crítico literario, $133-142$.

Hernández Guerrero, J.A. (1992b): «Cronología intelectual de Francisco Ayala», Anthropos 139: 26-27.

Hiriart, R. H. (1972a): Los recursos técnicos en la novelística de Francisco Ayala, Insula, Madrid.

HirIART, R. H. (1972b): Las alusiones literarias en la obra de Francisco Ayala, Iliseo Torres \& Sons, Madrid.

IRIZARRY, E. (1971): Teoría y creación literaria en Francisco Ayala, Gredos, Madrid.

López Calahorro, I. (2008): Francisco Ayala y el mundo clásico, Universidad de Granada, Granada.

Matamoro, B. (1992): «Francisco Ayala y la teoría de la novela», en A. SÁnchez Trigueros, A. Chicharro Chamorro (eds.), Francisco Ayala, teórico y crítico literario, 199-208.

Nicolás, C. (1988): Ramón y la Greguería. Morfología de un género nuevo, Universidad de Extremadura, Cáceres.

Orozco Vera, M. J. (1998): «Narradores y narratarios en la obra de Francisco Ayala (1949-1971)», en M. A. VÁZQUEZ MEdel (ed.), Francisco Ayala: el escritor en su siglo, Alfar, Madrid, pp. 149-162.

OrTega Garrido, A. (2012): Vanguardia y mundo clásico grecolatino en España, Iberoamericana Vervuert, Madrid \& Frankfurt.

Paredes NúÑEZ, S. (1992): «Manierismo y Barroco en la obra de Francisco Ayala: en torno a la introducción a El jardin de las delicias de Emilio Orozco", Anthropos 139: 73-74.

Sánchez Trigueros, A. \& Chicharro Chamorro, A. (eds.) (1992): Francisco Ayala, teórico y crítico literario, Diputación Provincial de Granada, Granada.

TAnnery, P. (1887): Pour l'histoire de la science hellène I. De Thalès à Empédocle, Félix Alcan, París.

VÁZquez Medel, M. A. (1992): «Francisco Ayala: teoría literaria vs. teoría de la comunicación», en A. Sánchez Trigueros, A Chicharro Chamorro (eds.), Francisco Ayala, teórico y crítico literario, Diputación Provincial de Granada, Granada, pp. 109-124.

Zlotescu, I. et al. (eds.) (1999): Ramón Gómez de la Serna. Obras Completas XI. Novelismo III, Círculo de Lectores/Galaxia Gutenberg, Barcelona.

Zlotescu, I. et al. (eds.) (2002): Ramón Gómez de la Serna. Obras Completas XIII. Novelismo V. Teatro, Círculo de Lectores/Galaxia Gutenberg, Barcelona. 